Оригинальные статьи / Original articles

https://doi.org/10.18619/2072-9146-2021-5-69-74 УДК 635.53/.54:631.53:581.19

Н.А. Голубкина ${ }^{1}$, В.А. Заячковский', И.В. Смирнова ${ }^{2}$, О. М. Выютнова ${ }^{2}$, B.А. Харченко ${ }^{1}$, А.И. Молдован ${ }^{1}$, Ю.П. Шевченко

' Федеральное государственное бюджетное научное учреждение "Федеральный научный центр овощеводства" (ФГБНУ ФНЦО)

143072 , Россия, Московская область,

Одинцовский район, п. ВНИИССОК,

ул. Селекционная, д. 14

${ }^{2}$ Ростовская овощная опытная станция по цикорию - филиал ФГБНУ ФНЦО

152130, Россия, Ярославская область

Ростовский район, с. Деревни

Конфликт интересов. Авторы заявляют об отсутствии конфликта интересов.

Вклад авторов: Все авторы участвовали в планировании и постановке эксперимента, а также в анализе экспериментальный данных и написании статьи.

Для цитирования: Голубкина Н.А., Заячковский В.А., Смирнова И.В., Выютнова О.М., Харченко В.А. Молдован А.И., Шевченко Ю.И.

Сравнительная оценка антиоксидантного статуса и содержания селена в семенах цикория (Cichorium intybus L.) и некоторых представителей сельдерейных культур. Овощи России. 2021;(5):69-74.

https://doi.org/10.18619/2072-9146-2021-569-74

Поступила в редакцию: 26.08.2021

Принята к печати: 15.09.2021

Опубликована: 11.10.202

Nadezhda A. Golubkina'

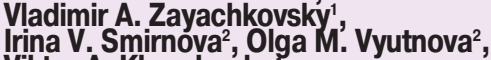

Irina V. Smirnova ${ }^{2}$, Olga
Viktor A. Kharchenko,

Anastasia I. Moldovan',

Yuri P. Shevchenko

'Federal State Budgetary Scientific Institution

Federal Scientific Vegetable Center (FSBSI FSVC 14, Selectsionnaya str., VNIIISOK, Odintsovo district, Moscow region, Russia, 143072

${ }^{2}$ Rostov Vegetable experimental station on chicory - Branch of the FSBSI FSVC

Derevni v., Rostov district, Yaroslavl region, 152130, Russia

Conflict of interest. The authors declare no conflict of interest.

Authors' Contribution: All authors contributed to the planning and setting up the experiment, as well as in the analysis of experimental data and writing of the article.

For citations: Golubkina N.A., Zayachkovsky V.A., Smirnova I.V., Vyutnova O.M., Kharchenko V.A Moldovan A.I., Shevchenko Yu.P. Comparative evaluation of antioxidant characteristics and selenium levels in seeds of Cichorium intybus L. and several representatives of Apiaceae plants. Vegetable crops of Russia. 2021; (5):69-74. (In Russ.) https://doi.org/10.18619/2072-91462021-5-69-74
Сравнительная оценка

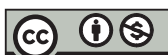

\section{антиоксидантного статуса \\ и содержания селена \\ в семенах цикория (Cichorium intybus L.)}

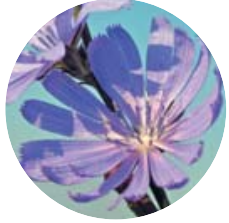

Резюме

Актуальность. Оценка пищевой ценности семян сельскохозяйственных растений является приоритетным направлением выявления новых значимых источников антиоксидантов для человека.

Материал и методы. Целью настоящего исследования было установление показателей антиоксидантного статуса и накопления селена семян цикория корневого (13 сортов) и сравнение полученных результатов с данными антиоксидантного статуса семян других корнеплодных культур: сельдерея (5 сортов), петрушки (2 сорта), пастернака (3 сорта) и моркови (7 сортов). Результаты. Установлено, что среди исследованных культур цикорий отличается в 3-4 раза более высокими уровнями аккумулирования селена семенами и сравнительно низкой общей антиоксидантной активностью и содержанием полифенолов. Аномально высокое содержание белка в семенах может явиться причиной легкого накопления микроэлемента селена, в то время как невысокий уровень антиоксидантной активности может быть связан с более низким содержанием эфирных масел. Выявлена прямая корреляция между содержанием полифенолов и общей антиоксидантной активностью для семян моркови ( $r=+0.924 ; P<0.01)$ и цикория $(r=0.803 ; P<0.01)$.

Ключевые слова: семена, цикорий, петрушка, сельдерей, морковь, пастернак, антиоксиданты, селен

\title{
Comparative evaluation of antioxidant characteristics and selenium levels in seeds of Cichorium intybus L. and several representatives of Apiaceae plants
}

\section{Abstract}

Relevance. Evaluation of nutritional value of seeds of agricultural crops is considered to be highly significant for revealing new sources of antioxidants for humans.

Material. The aim of the present investigation was antioxidant status and selenium accumulation levels by chicory seeds (13 cultivars) and comparison of the results with antioxidants status of seeds of other root vegetables: celery ( 5 cultivars), parsley ( 2 cultivars), parsnip ( 3 cultivars) and carrot ( 7 cultivars).

Results. Among agricultural crops studied chicory was characterized by 3-4 higher levels of selenium accumulation by seeds and relatively low total antioxidant activity and polyphenol content. Anomalously high protein content in chicory seeds may explain the efficiency of selenium accumulation while relatively low antioxidant activity may be connected with lower levels of essential oil. Direct correlations between polyphenol content and total antioxidant activity were demonstrated for carrot $(r=+0.924 ; P<0.01)$ and chicory $(r=$ 0.803; $P<0.01$ ) seeds.

Keywords: seeds, chicory, parsley, celery, carrot, parsnip, antioxidants, selenium 


\section{1. Введение}

последние годы уделяется все большее внимание новым природным источникам биологически активных веществ для человека, среди которых важное место занимают семена овощных культур [1,2]. Мало изученными в этом плане являются семена корнеплодных культур, применение которых к настоящему времени еще не получило широкого распространения. Отдельные работы в этой области свидетельствуют о высокой пищевой и фармацевтической ценности семян овощей, выращиваемых исключительно ради корнеплодов.

Семена цикория обыкновенного (Cichorium intybus L.) в России практически не используются. Между тем известно, что семена цикория составляют уникальный источник нутриентов, необходимых для питания [3]. Ying и Gui [4] показали, что семена большинства сортов цикория имеют высокое содержание белка, составляющего до 19\% в расчете на сухую массу, что в 1.6-2.4 раза выше, чем соответствующие значения для большинства зерновых культур, таких как пшеница, рис, кукуруза и ячмень. Качество белка семян цикория определяется высоким содержанием большинства эссенциальных аминокислот, таких как метионин, лизин, лейцин, изолейцин, фенилаланин и т.д. Кроме того, семена цикория содержат масла хороший источник как насыщенных, так и ненасыщенных жирных кислот [5], включая эссенциальную линоленовую кислоту (18:2n-6), составляющую более 76\% от общего содержания жирных кислот, включающих также мононенасыщенную олеиновую (18:1, n-9), стеариновую (18:0) и пальмитиновую кислоты (16:0) [4]. По сравнению с семенами люцерны семена цикория содержат более высокие уровни эссенциальных минералов, таких как K, Ca, Mg, Se и Zn [6]. Показано также, что семена цикория являются хорошим пищевым источником P, Ca, K, Mg, Na, Fe, Cu, Zn и Mn [4]. Из семян Cichorium intybus выделен сесквитерпеновый гликозид, обладающий значительным гепатопротекторным действием у крыс при воздействии четыреххлористого углерода, вызывающего разрушение печени [7]. За рубежом семена цикория используют для лечения печени [8].

Не менее значимыми в медицине являются семена и других корнеплодных сельскохозяйственных культур. Так, эссенциальное масло и экстракт семян моркови обладают кардио- и гепатопротекторным действием, восстанавливают когнитивную функцию, усиливая синтез ацетилхолина, снижают уровень холестерина, проявляют антибактериальное, противогрибковое, противовоспалительное, анальгетическое и ранозаживляющее действие, индуцируют сперматогенез [9].

Семена сельдерея (Apium graveolens) широко используются в качестве приправы. Однако они обладают также диуретическим свойством, благодаря чему способствуют снижению артериального давления. В Аювердической медицине семена сельдерея используют для лечения простуды и воспаления легких. Семена сельдерея применяют также для лечения артрита, снижают уровень холестерина, замедляют развитие рака легких и рака желудка, приводя к апоптозу раковых клеток $[10,11]$. Семена проявляют антиоксидантные, противовоспалительные и анальгетические свойства [12].

Семена петрушки обладают антимикробным, противоревматическим, противоартритным действием, улучшают пищеварение, обладают диуретическим действием. Их используют при лечении лихорадки и снижения артериального давления, снижения воспалительных процессов, повышения либидо [13]. Эссенциальное масло семян проявляет антиоксидантное, противомикробное, противораковое действие [14], Основными действующими компонентами масла семян петрушки являются миристицин и апиол. В биологическом плане петрушка обладает снотворным, спазмолитическим, ветрогонным, мочегонным, отхаркивающим и тонизирующим средством для желудка и почек. Смесь семян и корней усиливает лактацию и сокращение матки. Показано анальгетическое действие водно-спиртового экстракта семян петрушки на мышах [15]. Водный экстракт семян обладает слабительным действием [16].

Микроэлемент селен является эссенциальным для млекопитающих, оптимизируя в организме человека антиоксидантный статус, предотвращая возникновение и развитие онкологических и кардиологических заболеваний [17]. Поскольку основным источником селена для человека является пища, то крайне важным представляется оценка уровней накопления микроэлемента различными сельскохозяйственными культурами, в том числе и семенами. Выявленные защитные свойства селена в отношении вирусных заболеваний, включая Ковид-19 [18], создают дополнительный стимул для таких исследований.

Целью настоящей работы была сравнительная оценка антиоксидантного статуса и уровней накопления микроэлемента селена семенами цикория и отдельных корнеплодных культур: моркови, петрушки, пастернака и сельдерея.

\section{2. Материалы и методы}

\section{1.Характеристика исследуемого материала}

В работе использовали семена 2018 года 13 сортов цикория корневого (Cichorium intybus L) коллекций Ростовской опытной станции по цикорию и ФГБНУ ФНЦО и семена 2019 года 2-х сортов корневой петрушки (Сахарная и Золушка), 4-х сортов корневого сельдерея (Юдинка, Егор, Добрыня, Грибовский), 3-х сортов пастернака (Жемчуг, Круглый, Белый аист), 5 сортов и 2-х гибридов 
Таблица 1. Среднемесячные температура и осадки в 2018-2019 годах

Table 1. Mean month temperature and precipitation, 2018-2019

\begin{tabular}{|c|c|c|c|c|}
\hline \multirow{2}{*}{$\begin{array}{l}\text { Meсяц } \\
\text { Month }\end{array}$} & \multicolumn{2}{|c|}{2018} & \multicolumn{2}{|c|}{2019} \\
\hline & $\begin{array}{c}\text { Средняя температура }\left({ }^{\circ} \mathrm{C}\right) \\
\text { Mean temperature }(\mathrm{oC})\end{array}$ & $\begin{array}{c}\text { Осадки (мм) } \\
\text { Precipitation (mm) }\end{array}$ & $\begin{array}{c}\text { Средняя температура }\left({ }^{\circ} \mathrm{C}\right) \\
\text { Mean temperature (oC) }\end{array}$ & $\begin{array}{c}\text { Осадки (мм) } \\
\text { Precipitation (mm) }\end{array}$ \\
\hline Май Мау & 16.2 & 61 & 16.3 & 57 \\
\hline Июнь June & 17.3 & 56 & 19.6 & 64 \\
\hline Июль July & 20.5 & 92 & 16.8 & 69 \\
\hline Август August & 19.8 & 28 & 16.4 & 57 \\
\hline
\end{tabular}

моркови (Московская зимняя, Нантская-11, $F_{1}$ Риф, Шантане, Минор, F1 Надежда, Марлинка) селекции ФГБНУ ФНЦО.

Среднемесячная температура и количество осадков за исследованный период приведены в таблице 1.

\section{2. Определение антиоксидантной активно- сти и содержания полифенолов}

Перед проведением анализа семена высушивали до постоянной массы при $70^{\circ} \mathrm{C}$.

Для определения антиоксидантной активности и содержания полифенолов 0.5 г семян растирали в 70\% спирте и экстрагировали при $80^{\circ} \mathrm{C}$ в течение часа. После этого смесь охлаждали, переносили количественно с мерную колбу на 25 мл и доводили до метки 70\% этиловым спиртом. Смесь перемешивали и фильтровали.

\subsection{1. Определение полифенолов}

В мерную колбу на 25 мл добавляли 1 мл спиртового экстракта семян, 2.5 мл насыщенного раствора карбоната натрия и 0.25 мл разбавленного вдвое реактива Фолина-Чиокалтеу. Смесь интенсивно перемешивали, доводили до метки дистиллированной водой, еще раз перемешивали и оставляли при комнатной температуре на 1 час, после чего определяли величину поглощения полученного раствора при 730 нм на спектрофотометре (Unico 2804 UV, USA). Концентрацию полифенолов рассчитывали по калибровочной кривой, построенной по пяти концентрациям галловой кислоты.

\subsection{2. Антиоксидантная активность (AOA)}

Уровень антиоксидантной активности семян устанавливали редокс-титрованием этанольными экстрактами семян $0.01 \mathrm{H}$ раствора $\mathrm{KMnO}_{4}$. Обесцвечивание раствора $\mathrm{KMnO} 4$ до бесцветного $\mathrm{Mn}^{+2}$ в этом процессе, отражает количество антиоксидантов, растворенных в $70 \%$ этаноле. Результаты выражали в мг-эквивалентах галловой кислоты на г сухой массы [19].

\section{3. Содержание селена}

Для определения содержания селена использовали микрофлуорометрический метод анализа [20], основанный на мокром сжигании образцов смесью азотной и хлорной кислот, восстановлении шестивалентного селена до $\mathrm{Se}+4$ и конденсации образующейся селенистой кислоты с 2,3-диаминонафталином. Содержание селена рассчитывали по величине флуоресценции продукта конденсации пиазоселенола при длине волны возбуждения 374 нм и эмиссии 519 нм.

\section{4. Статистический анализ}

Статистическую обработку материала проводили с использование компьютерной статистической программы Excel.

\section{3. Результаты и обсуждения}

\section{1. Показатели антиоксидантного статуса и} уровней накопления селена семенами

Представленные в таблице 2 данные о содержание селена, полифенолов и общей антиоксидантной активности семян цикория, корневого сельдерея и петрушки, моркови и пастернака позволяют выделить две особенности: 1) необычно высокие показатели аккумулирования селена семенами цикория и 2) высокие уровни антиоксидантной активности семян сельдерея и петрушки.

Действительно, сравнительная оценка уровней накопления селена семенами исследованных культур показала снижение селенаккумулирующей способности в ряду: цикорий > петрушка = морковь = пастернак > сельдерей (рис.1а). Показательно, что согласно литературным данным наиболее легко обогащается селеном именно цикорий без заметного проявления токсического эффекта микроэлемента, что дает возможность получения функциональных продуктов питания с повышенным содержанием микроэлемента [2123]. Более того, установлено, что цикорий салатный (Cichorium endivia) является выраженным аккумулятором селена [24]. Однако данных о накопле- 
Таблица 2. Общее содержание полифенолов (TP), селена (Se) и уровень общей антиоксидантной активности (AOA) семян цикория, петрушки, сельдерея, пастернака и моркови

Table 2. Total phenolics (TP), selenium (Se) content and total antioxidant activity

(AOA) of chicory, parsley, celery, parsnip and carrot seeds

\begin{tabular}{|c|c|c|c|c|}
\hline $\begin{array}{c}\text { Вид } \\
\text { Species }\end{array}$ & $\begin{array}{l}\text { Copt } \\
\text { Cultivar }\end{array}$ & $\begin{array}{c}\text { AOA, мг ГКЭ/г c.м. } \\
\text { mg GAE g/d.w. }\end{array}$ & $\begin{array}{c}\text { TP, мг ГКЭ/г с.м. } \\
\text { mg GAE/g d.w. }\end{array}$ & $\begin{array}{l}\text { Se, мкг/кг с.м. } \\
\mu \mathrm{g} / \mathrm{kg} \text { d.w. }\end{array}$ \\
\hline \multirow{13}{*}{$\begin{array}{l}\text { Цикорий } \\
\text { Chicory }\end{array}$} & Ростовский (Россия) Rostovsky (Russia) & $10.3 c$ & $9.0 \mathrm{ab}$ & $153 b$ \\
\hline & Подлуга Куявска (Польша) Podluga Cuyavska (Poland) & $11.2 \mathrm{~b}$ & $8.2 b$ & $116 \mathrm{de}$ \\
\hline & TidWog (Франция France) & $11.1 \mathrm{~b}$ & $9.6 a b$ & $106 e$ \\
\hline & Cassel (Франция France) & $11.5 b$ & $10.4 a$ & $92 e$ \\
\hline & Orchies (Франция France) & $11.0 \mathrm{~b}$ & $10.4 a$ & $97 e$ \\
\hline & Novipa (Бельгия Belgium) & $11.1 \mathrm{~b}$ & $10.4 a$ & $181 \mathrm{a}$ \\
\hline & Wixor (Голландия Holland) & 12.0ab & $10.0 \mathrm{a}$ & $138 \mathrm{bc}$ \\
\hline & Spicak (Чехия Chess rep) & $10.2 \mathrm{C}$ & 9.3ab & $111 \mathrm{ed}$ \\
\hline & Luxor (Голландия Holland) & $11.8 \mathrm{~b}$ & $10.9 a$ & $126 \mathrm{~cd}$ \\
\hline & Albino RVp.k-41 (Бельгия Belgium) & $13.3 a$ & $11.1 \mathrm{a}$ & 97ed \\
\hline & Rexor RS (Голландия Holland) & $10.6 \mathrm{c}$ & $9.1 \mathrm{ab}$ & $131 \mathrm{~cd}$ \\
\hline & Berguce (Франция France) & $10.8 \mathrm{c}$ & $10.0 \mathrm{ab}$ & $131 \mathrm{~cd}$ \\
\hline & Sleszka (Чехия Chess rep) & $11.9 \mathrm{bc}$ & $10.8 \mathrm{a}$ & $128 \mathrm{~cd}$ \\
\hline \multirow{2}{*}{$\begin{array}{c}\text { Петрушка } \\
\text { Parsley }\end{array}$} & Сахарная Sakharnaya & $51.2 a, b$ & $10.0 \mathrm{e}$ & $22 \mathrm{~g}$ \\
\hline & Золушка Zolushka & $46.5 \mathrm{~b}, \mathrm{c}$ & 10.3 e & $89 \mathrm{~b}$ \\
\hline \multirow{4}{*}{$\begin{array}{c}\text { Сельдерей } \\
\text { Selery }\end{array}$} & Грибовский Gribovsky & $40.0 \mathrm{c}, \mathrm{d}$ & $13.0 \mathrm{~b}, \mathrm{c}$ & $10 \mathrm{j}$ \\
\hline & Erop Egor & $42.5 \mathrm{c}, \mathrm{d}$ & $15.1 \mathrm{a}, \mathrm{b}$ & $30 \mathrm{~g}$ \\
\hline & Добрыня Dobrynya & $40.9 \mathrm{c}, \mathrm{d}$ & $13.8 a, b$ & $25 \mathrm{~g}$ \\
\hline & Юдинка Judinka & $40.0 \mathrm{c}, \mathrm{d}$ & $11.8 \mathrm{c}, \mathrm{d}, \mathrm{e}$ & $13 \mathrm{j}$ \\
\hline \multirow{3}{*}{$\begin{array}{c}\text { Пастернак } \\
\text { Parsnip }\end{array}$} & Круглый Krugly & $17.9 \mathrm{f}, \mathrm{g}$ & $9.8 \mathrm{e}$ & 37 e \\
\hline & Белый аист Bely aist & $19.0 \mathrm{f}$ & $11.3 \mathrm{~d}, \mathrm{e}$ & $51 \mathrm{c}$ \\
\hline & Жемчуг Zhemchug & $17.9 \mathrm{f}, \mathrm{g}$ & $9.5 \mathrm{e}$ & $31 \mathrm{f}, \mathrm{g}$ \\
\hline \multirow{7}{*}{$\begin{array}{l}\text { Морковь } \\
\text { Carrot }\end{array}$} & Московская зимняя M.Zimnyaya & $15.6 \mathrm{~g}, \mathrm{~h}$ & $9.2 \mathrm{e}, \mathrm{g}$ & $56 \mathrm{c}$ \\
\hline & $F_{1}$ Надежда $F_{1}$ Nadezhda & $13.4 \mathrm{~h}, \mathrm{j}$ & $7.6 \mathrm{f}, \mathrm{g}$ & $40 \mathrm{~d}, \mathrm{e}$ \\
\hline & Минор Minor & $15.8 \mathrm{~g}, \mathrm{~h}$ & 10.3 e & $34 \mathrm{f}$ \\
\hline & Нантская-11 Nantskaya-11 & $14.1 \mathrm{~h}$ & $7.5 f$ & $33 \mathrm{f}$ \\
\hline & $F_{1}$ Риф $F_{1}$ Riff & $12.5 j$ & $6.5 f$ & $54 \mathrm{c}$ \\
\hline & Марлинка Marlinka & $13.0 \mathrm{j}$ & $7.8 \mathrm{f}, \mathrm{g}$ & $38 d$ \\
\hline & Шантане Shantane & $12.5 \mathrm{j}$ & $7.1 \mathrm{f}$ & $42 \mathrm{~d}, \mathrm{e}$ \\
\hline
\end{tabular}

AOA -общая антиоксидантная активность; TP -полифенолы

Для семян каждого вида значения в столбцах с одинаковыми индексами статистически не различаются согласно тесту Дункана при $P<0.05$

AOA - total antioxidant activity; TP - polyphenols

For each species within each column, values with the same letters do not differ statistically according to Duncan test at $p<0.05$

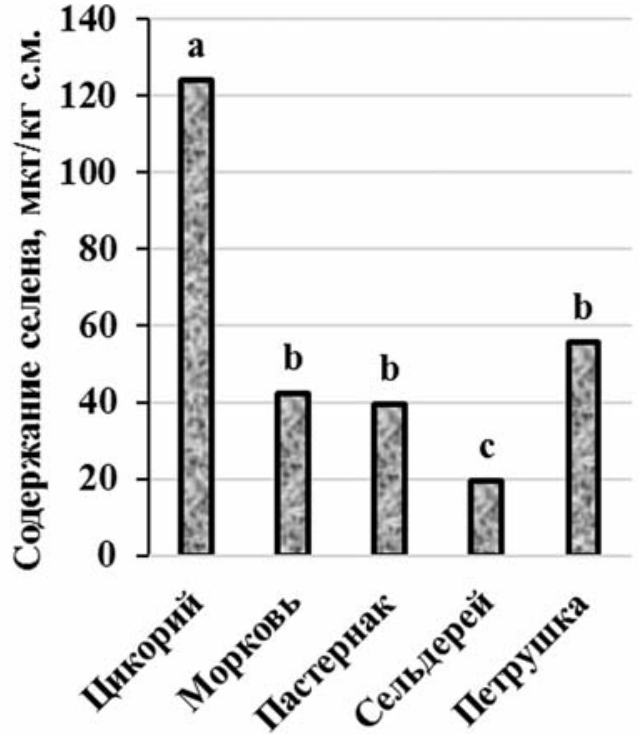

(a)

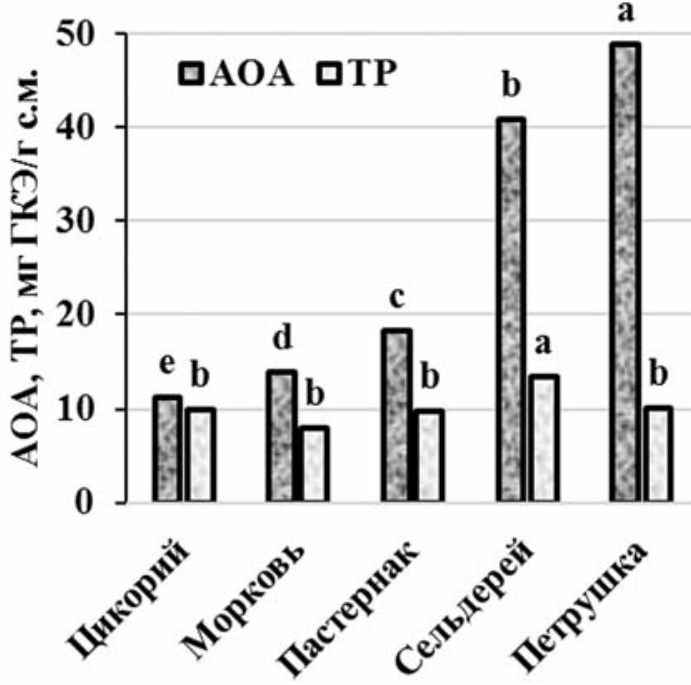

(b)

Рис.1. Средние уровни аккумулирования селена (Se) (a), общей антиоксидантной активности (AOA) и полифенолов (TP) (b) в семенах корнеплодных культур

Значения с одинаковыми индексами статистически не различаются согласно тесту Дункана при $P<0.05$ Fig. 1. Mean levels of selenium (Se) (a) accumulation, total antioxidant activity (AOA) and polyphenols

(TP) (b) in seeds of root crops Values with similar indexes do not differ statistically according to Duncan test at $P<0.05$ 


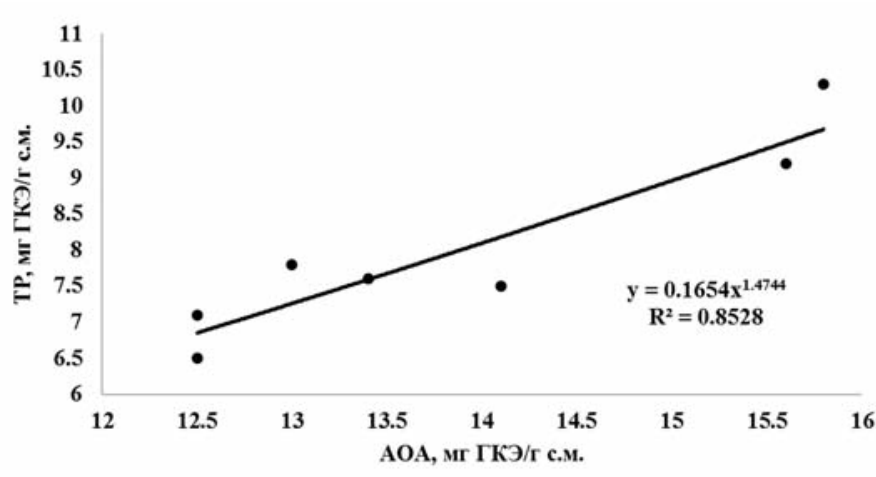

(a)

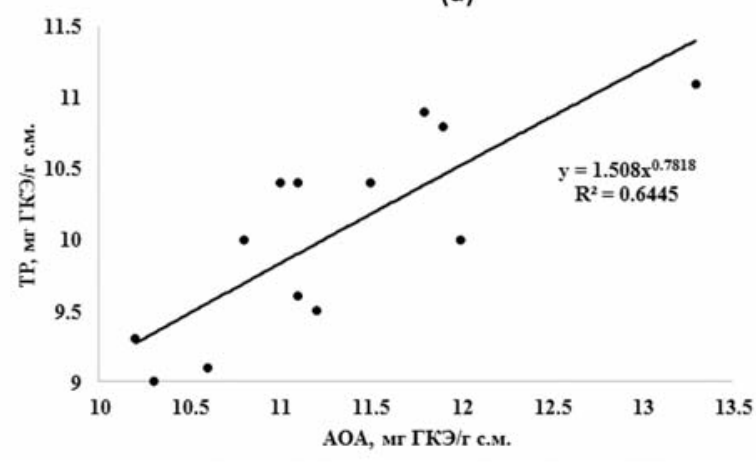

(b)

Рис. 2. Взаимосвязь между показателями общей антиоксидантной активности (АОA) и уровнем накопления полифенолов (TP) в семенах моркови (а) и цикория (b) ( $r=0.924$ и $r=0.803$ соответственно)

Fig. 2. Relationship between total antioxidant activity (AOA) and polyphenol content (TP) in carrot (a) and chicory (b) seeds ( $r=0.924$ and $r=0.803$ accordingly)

нии селена семенами цикория как корневого, так и салатного, в настоящее время нет.

Также следует отметить, что межсортовые различия по всем исследованным показателям как для семян цикория, так и петрушки, сельдерея, пастернака и моркови выражены слабо и не превышают $20 \%$.

Интересно отметить, что по сравнению с листовыми формами сельдерейных культур цикорий по содержанию селена в семенах может сравниться только с данными для двух сортов листовой петрушки: Бриз и Москвичка [1]. Вопрос получения цикория с повышенным содержанием селена имеет особое значение в связи с потенциальной возможностью получения функциональных продуктов питания с повышенным содержанием микроэлемента и выявленным протекторным действием соединений селена по отношению к вирусным и хроническим заболеваниям, выключая Ковид-19 $[18,25,26]$.

С другой стороны, уровень общей антиоксидантной активности семян выбранных культур свидетельствует о сравнительно низких показателях у цикория (рис.1b). Напротив, семена петрушки и сельдерея отличались наибольшей антиоксидантной активностью. Такое явление может быть связано с более высоким содержанием эфирных масел в семенах петрушки, сельдерея и пастернака по сравнению с семенами цикория и моркови. В пользу этого указывают высокие показатели антиоксидантной активности и содержания эфирных масел петрушки, пастернака и сельдерея [27-30] и низкая вариабельность накопления полифенолов семенами указанных культур (рис.1b). Известно, что основными компонентами эфирных масел петрушки с высокой антиоксидантной активностью являются миристицин $34.18 \%$, $\alpha$-пинен $16.14 \%$ и апиол $15.69 \%$ [27]. У семян сельдерея основным компонентом эфирного масла является лимонен [29]. У семян моркови содержание эфирного масла в 3 раза ниже, чем в семенах петрушки, а основными компонентами масла являются каротол (66.78\%), дауцен (8.74\%) и фарнезен (5.86\%) [30].

\section{2. Взаимосвязь между общей антиоксидант-} ной активностью и содержанием полифенолов

Известно, что в большинстве растительных организмов существует прямая взаимосвязь между содержанием полифенолов и общей антиоксидантной активностью [19]. Данные, полученные в настоящей работе на семенах цикория и моркови, подтверждают эту особенность, однако дополнительно указывают, что такая взаимосвязь строго видоспецифична. Так, данные рис.2а свидетельствуют о разном уровне корреляционных взаимосвязей: у семян цикория доля полифенолов в общей антиоксидантной активности значительно выше, чем у семян моркови, где важную роль в общей антиоксидатной активности играют эфирные масла.

Показательно, что семена большинства сельдерейных культур (11 видов) [1] проявляют единую корреляцию между общей антиоксидантной активностью и содержанием полифенолов. Результаты представленной выше оценки взаимосвязей между общей антиоксидантной активностью и содержанием полифенолов в семенах моркови и цикория, а также данные, полученные для других сельдерейных культур [1,31], подтверждают, что такая взаимосвязь типична для индивидуальных семейств, в частности, из данных рис. 1 и 2 хорошо видны значимые различия для семян цикория (семейство Астровые) и моркови (семейство Сельдерейные).

\section{Заключение}

Проведение сравнительной оценки антиоксидантного статуса семян корнеплодных культур свидетельствует о высокой пищевой ценности и, в частности, высоком содержании селена в семенах цикория, что указывает на перспективность использования семян цикория в пищевой промышленности и в медицине не только как источника белка, но также и микроэлемента селена. 


\section{Об авторах:}

Надежда Александровна Голубкина - главный научный сотрудник лабораторно-аналитического отдела, segolubkina45@gmail.com, https://orcid.org/0000-0003-1803-9168

Владимир Александрович Заячковский - кандидат С.-х. наук, старший научный сотрудник лаборатория селекции и семеноводства корнеплодных культур, https://orcid.org/0000-0001-9821-5381, vladimir89854217114@mail.ru

Ирина Викторовна Смирнова - руководитель Ростовской овощной опытной станции по цикорию - филиала ФГБНУ ФНЦО

Ольга Михайловна Вьютнова - кандидат с.-х. наук старший научный сотрудник, olga.vjutnova@yandex.ru

Виктор Александрович Харченко - кандидат с.-х. наук, заведующий лабораторией селекции и семеноводства зеленных, пряно-вкусовых и цветочных культур,

https://orcid.org/0000-0003-2775-9140, kharchenkoviktor777@gmail.com Анастасия Ильинична Молдован - аспирант, мл. научный сотрудник лаборатории селекции и семеноводства зеленных,

пряно-вкусовых и цветочных культур, nastiamoldovan@mail.ru

Юрий Петрович Шевченко - ведущий научный сотрудник

лаборатории селекции и семеноводства зеленных,

пряно-вкусовых и цветочных культур

\section{- Литература / References}

1. Golubkina N., Kharchenko V., Moldovan A., Zayachkovsky V., Stepanov V. Pivovarov V., Sekara A., Tallarita A., Caruso G. Nutritional Value of Apiaceae Seeds as Affected by 11 Species and 43 Cultivars. Horticulturae. 2021;(7):57. https://doi.org/ .3390/horticulturae7030057

2. Nwafor I.C., Shale K., Achilonu M.C. Chemical Composition and Nutritive Benefits of Chicory (Cichorium intybus) as an Ideal Complementary and/or Alternative Livestock Feed Supplement. Scientific World Journal. 2017;(2017):343928 https://doi.org/10.1155/2017/7343928

3. Janda K., Gutowska I., Geszke-Moritz M., Jakubczyk K. The Common Cichory (Cichorium intybus L.) as a Source of Extracts with Health-Promoting Properties - A Review. Molecules 2021;(26):1814. https://doi.org/10.3390/molecules26061814 4. Ying G.W., Gui L.J. Chicory seeds: a potential source of nutrition for food and feed Journal of Animal and Feed Sciences. 2012;13 (2):1736-1746.

5. Marcone M.F., Jahaniaval F., Aliee H., Kakuda Y. Chemical characterization of Achyranthes bidentata seed. Food Chemistry. 2003;81(1):7-12.

6. Plaza L., De Ancos B., Cano M.P. Nutritional and health-related compounds in sprouts and seeds of soybean (Glycine max), wheat (Triticum aestivum.L) and alfalfa (Medicago sativa) treated by a new drying method. European Food Research and Technology. 2003;216(2):138-144.

7. Ahmed B., Khan S., Masood M.H., Siddique A.H. Anti-hepatotoxic activity of cichotyboside, a sesquiterpene glycoside from the seeds of Cichorium intybus Journal of Asian Natural Products Research. 2008;10(3-4):223-231.

8. Street R.A., Sidana J., Prinsloo G. Cichorium intybus: Traditional Uses Phytochemistry, Pharmacology, and Toxicology Evidence-Based Complementary and Alternative Medicine. 2013;(2013):579319.

http://dx.doi.org/10.1155/2013/579319

9. da Silva Dias J.C. Nutritional and Health Benefits of Carrots and Their Seed Extracts. Food and Nutrition Sciences. 2014;5(22):2147-2156. doi: 10.4236/fns. 2014.522227

10. Khuon O.S. Role of Aqueous Extract of Apium graveolens Seeds Against the Haematotoxicity Induced by Carbon Tetrachloride. Journal of College of Education for Pure Science. 2012;2(1):10-23.

11. Mansi K., Abushoffa A.M., Disi A., Aburjai T. Hypolipidemic effects of seed extract of celery (Apium graveolens) in rats. Pharmacognosy magazine. 2009;5(20):301 doi:10.4103/0973-1296.58149

12. Mustafa T.I., Abdullah Z.K., Mahmood N.M.S., Gorony S.M.A., Chato K.B. Shareef R.M.M. Effects of Celery Seed Extracts on Some Haematological and Biochemical Parameters in Albino Rats Treated with Gentamicin. Volume 4 Special Issue: 3rd International Conference on Health \& Medical Sciences: Insight into Advanced Medical Research (ICHMS 2019). doi: 10.24017/science.2019.ICHMS.12

13. Sarwar S.S., Ayyub M.A., Rezgui M., Nisar S., Jilani M.I. Parsley: A review of habitat, phytochemistry, ethnopharmacology and biological activities. International Journal of Chemical and Biochemical Sciences IJCBS. 2016;(9):49-55

14. Hanif M.A., Al-Maskari M.Y., Al-Maskari A., Al-Shukaili A., Al-Maskari A.Y.,. AlSabahi. J.N. Essential oil composition, antimicrobial and antioxidant activities of unexplored Omani basil. Journal of Medicinal Plants Research. 2011;5(5):751-757. 15. Behtash N., Kargarzadeh F., Shafaroudi H. Analgesic effects of seed extract from Petroselinum crispum (Tagetes minuta) in animal models. Toxicology Letters. 2008;(180):S127-S128.

16. Kreydiyyeh S., Usta J., Kaouk I., Al-Sadi R. The mechanism underlying the laxative properties of parsley extract. Phytomedicine. 2001;8(5):382-388.

17. Голубкина Н.А., Папазян Т.Т. Селен в питании. Растения, животные, человек. М., Печатный город. 2006. [Golubkina N.A., Papazyan T.T. Selenium in

\section{About the authors:}

Nadezhda A. Golubkina - Doc. Sci. (Agriculture),

corresponding author, leading researcher of laboratory-analytical department, segolubkina45@gmail.com, https://orcid.org/0000-0003-1803-9168 Vladimir A. Zayachkovsky - Cand. Sci. (Agriculture),

Senior Researcher, Laboratory of Breeding and Seed Production

of Root Crops, https://orcid.org/0000-0001-9821-5381,

vladimir89854217114@mail.ru

Irina V. Smirnova - Head of the Rostov Vegetable Experimental Station

on chicory - branch of FSBSI FSVC

Olga M. Vyutnova - Cand. Sci. (Agriculture),

Senior Researcher, olga.vjutnova@yandex.ru

Viktor A. Kharchenko - Cand. Sci. (Agriculture), Head of Laboratory of

Selection And Seed Production Of Green,

Spice-Flavoring and Flower Crops,

https://orcid.org/0000-0003-2775-9140, kharchenkoviktor777@gmail.com

Anastasia I. Moldovan - Graduate Student, junior researcher,

laboratory of Selection And Seed Production Of Green,

Spice-Flavoring and Flower Crops, nastiamoldovan@mail.ru

Yuri P. Shevchenko - Senior Researcher of Laboratory

of Selection And Seed Production Of Green,

Spice-Flavoring and Flower Crops

Nutrition. Plants, animals, human beings. Moscow, Pechatny Gorod, 2006. (In Russ.)]

18. Zhang H.Y., Zhang A.R., Lu Q.B., Zhang X-A., Zhang Z-J., Guan X-G., Che

T-L., Yang Y, H. Li, Liu W., Fang L-Q. Association between fatality rate of COVID19 and selenium deficiency in China. BMC Infect Dis. 2021;(21):452.https://doi.org/10.1186/s12879-021-06167-8

19. Голубкина Н.А, Кекина Е.Г, Молчанова А.В., Антошкина М.С., Надежкин С.М., Солдатенко А.В. Антиоксидантны растений и методы их определения. М., Инфрpa-M. 2021. [Golubkina N.A., Kekina H.G., Molchanova A.V., Antoshkina M.S. Nadezhkin S.M., Soldatenko A.V. Antioxidants of plants and methods of their determination. M., Infra-M, 2021. (In Russ.)]

20. Alfthan, G.V. A micromethod for the determination of selenium in tissues and biological fluids by single-test-tube fluorimetry. Anal. Chim. Acta. 1984;(65):187-194.

21. Stibilj V., Smrkolj P., Jaćimović R., Osvald J. Selenium uptake and distribution in chicory (Cichorium intybus L.) grown in an aeroponic system. Acta agriculturae Slovenica. 2011;97(3):189-196. DOI: 10.2478/v10014-011-0013-9

22. Germ M., Marsic M.K., Croflič A., Jerše A.,.Stibilj V., Golob A. Significant Accumulation of lodine and Selenium in Chicory (Cichorium intybus L. var. foliosum Hegi) Leaves after Foliar Spraying. Plants. 2020;9(12):1766. doi: 10.3390/plants9121766

23. Sabatino L., Ntatsi G., lapichino G., D'Anna F., De Pasquale C. Effect of Selenium Enrichment and Type of Application on Yield, Functional Quality and Mineral Composition of Curly Endive Grown in a Hydroponic System. Agronomy. 2019;(9):207. doi:10.3390/agronomy9040207

24. Голубкина Н.А., Шевченко Ю.П., Харченко В.А., Кошелева О.В., Солдатенко А.В. Биохимическая характеристика и элементный состав цикория салатного (Cichorium intybus L.) сорт Конус. Овощи России. 2019;(3):80-86. https://doi.org/10.18619/2072-9146-2019-3-80-86 [Golubkina N.A., Shevchenko Yu.P., Kharchenko V.A., Kosheleva O.V., Soldatenko A.V. Biochemical characteristic and element composition of Cichorium intybus, Konus cultivar. Vegetable crops of Russia. 2019;(3):80-86. (In Russ.) https://doi.org/10.18619/2072-9146-2019-3-8086]

25. Kieliszeka M., Lipinski B. Selenium supplementation in the prevention of coronavirus infections (COVID-19). Medical Hypothesis. 2020;(143):109878 https://doi.org/10.1016/j.mehy.2020. 109878

26. Khatiwada S., Subedi A. A Mechanistic Link Between Selenium and Coronavirus Disease 2019 (COVID-19). Curr Nutr Rep. 2021;(10):125-136.

https://doi.org/10.1007/s13668-021-00354-4

27. Saqqa G.A., Alian A., Ismail F., Ramzy F. Chemical composition of rocket, thyme and parsley essential oils and their effect on some fungi and aflatoxin production. MOJ Toxicol. 2018;4(4):77-282. DOI: 10.15406/mojt.2018.04.00112

28. El-Beltagi H.S., Dhawi F., Aly A.A., El-Ansary A.E. Chemical compositions and biological activities of the essential oils from gamma irradiated celery (Apium graveolens L.) seeds. Notulae Botanicae Horti Agrobotanici Cluj-Napoca. 2020;48(4):2114-2133. https://doi.org/10.15835/nbha48412115

29. Zorga J., Kunicka-Styczy'nska A., Gruska R., Smigielski K. Ultrasound-Assisted Hydrodistillation of Essential Oil from Celery Seeds (Apium graveolens L.) and Its Biological and Aroma Profiles. Molecules. 2020;(25):5322. doi:10.3390/molecules25225322

30. Özcan M., Chalchat J.C. Chemical composition of carrot seeds (Daucus carota L.) cultivated in Turkey. Characterization of the seed oil and essential oil. Grasas $y$ Aceites. 2007;58(4):359-365. doi: 10.3989/gya.2007.v58.i4.447

31. Golubkina N.A., Kharchenko V.A., Caruso G. Selenium: prospects of functional food production with high antioxidant activity Reference Series in Phyto-chemistry. Plant Antioxidants and Health, edited by H. Ekiert, K.G. Ramawat. J Arora. 2021, Elsevier. 